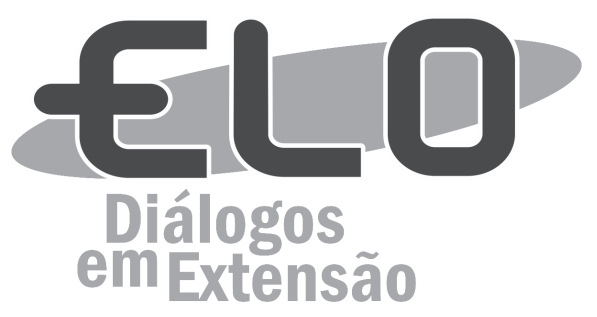

\title{
Engenharia Pública: da necessidade social e urbana à experiência de Engenharia Civil e Arquitetura
}

\author{
Pedro Paulo Mingote Martins ${ }^{1}$, Priscilla Voss Ventorim², Daniely Camargos
} Lucarelli, José Maria Franco de Carvalho ${ }^{4}$

\begin{abstract}
Resumo: O Engenharia Pública é um projeto de extensão que possui caráter social e oferece gratuitamente às comunidades carentes de Viçosa e região serviços relacionados à Engenharia Civil e Arquitetura em função da demanda e da necessidade da população. A partir da elaboração de soluções economicamente viáveis $e$ tecnicamente adequadas para a problemática das obras no espaço urbano, o Engenharia Pública promove projetos que buscam o protagonismo e o desenvolvimento social, como o da construção do Centro Educacional e Ação Social São Sebastião e o curso de capacitação em construção civil, segurança do trabalho e empreendedorismo em parceria com a Casa da Mulher. Como resultados foram alcançadas melhorias na infraestrutura urbana, a fomentação do aprendizado prático dos estudantes em sua área de atuação e o desenvolvimento de ações comunitárias.
\end{abstract}

Palavras-chave: Desenvolvimento Social. Voluntariado. Desenvolvimento Urbano.

Área Temática: Políticas Públicas; Urbanização.

\section{Public Engineering: from social and urban necessities to Civil Engineering and Architecture experience}

Abstract: Public Engineering is a socially oriented university extension project that provides freely Civil Engineering and Architecture services to low-income communities from Viçosa and surroundings due to their demands and needs. Through the development of economically viable and technically appropriate solutions to the work problems in the urban space, the Public Engineering promotes projects that seek the role and social development. For instance, the construction of the Educational Center and Social Action São Sebastião and the civil construction, labor safety and entrepreneurship training courses in partnership with the House of the Women. As results were achieved improvements in urban infrastructure, the fostering of practical learning of students in their area of expertise and the development of communitarian actions.

Keywords: Social development. Volunteering. Urban Development.

\section{Ingenieria Publica: de la necesidad social y urbana a la experiencia de Ingenieria Civil y Arquitectura}

Resumen: El Ingeniería Publica es un proyecto de extensión que tiene un carácter social y ofrece gratuitamente a la comunidad de Viçosa y a sus entornos servicios de ingeniería civil y arquitectura en función de la demanda y necesidad de la población. A partir de la elaboración de soluciones económicamente viables y técnicamente adecuadas para la problemática de las obras en el espacio urbano, el Ingeniería Publica promueve proyectos

\footnotetext{
${ }^{1}$ Aluno do curso de Engenharia Civil da Universidade Federal de Viçosa, participante do projeto, Endereço: Rua Fuad Chequer, No 70, Apto 202, Bairro Clélia Bernardes, Viçosa-MG, Telefone: (31) 9419-4542, e-mail: martins.engciv@gmail.com

${ }^{2}$ Aluna do curso de Engenharia Civil da Universidade Federal de Viçosa, participante do projeto, Endereço: Rua José Antônio Rodrigues, No 110 , Apto 301 , Bairro Centro, Viçosa-MG, Telefone: (28) 99958-8882, e-mail: priscillavoss@hotmail.com

${ }^{3}$ Aluna do curso de Engenharia Civil da Universidade Federal de Viçosa, participante do projeto.

${ }^{4}$ Professor do Departamento de Engenharia Civil da Universidade Federal de Viçosa, coordenador do projeto.
} 
que buscan el protagonismo y el desenvolvimiento social, como, el de la construcción del Centro Educacional y Acción Social San Sebastián y el curso de capacitación en construcción civil, seguridad laboral y emprendimiento, en conjunto con la Casa de la Mujer. Como resultados se logró mejorías en la infraestructura urbana, además de la fomentación del conocimiento práctico de los estudiantes en su área de actuación y del desenvolvimiento de acciones comunitarias.

Palabras clave: Desenvolvimiento social. Voluntariado. Desenvolvimiento Urbano.

\section{Introdução e Justificativa}

Comumente, as construções no Brasil são realizadas sem os respaldos técnico e profissional necessários a fim de assegurar qualidade e segurança à obra. Nenhuma delas, porém, deveria ser executada de tal forma. O projeto de engenharia é que garante a permanência da construção numa estrada estreita margeada por dois precipícios: de um lado o da insegurança e, do outro, o do desperdício (SANTOS apud MILLEN, 2012). As causas dessa conduta estão arraigadas, de forma preocupante, na cultura brasileira, e vão desde a falta de recursos financeiros para contratar um profissional capacitado até a falta de conhecimento acerca da importância dos serviços prestados por esse tipo de profissional. Como consequência, essas construções apresentam problemas diversos que, em casos catastróficos, afetam não só a comunidade em que está inserida, mas, sim, a cidade como um todo.

Sendo assim, constatou-se a necessidade da criação do projeto de extensão Engenharia Pública, que tem como objetivo oferecer gratuitamente à população carente de Viçosa e região serviços relacionados às áreas de atuação da Engenharia Civil e Arquitetura, e, além disso, por meio de consultorias, informações e discussões, buscar soluções economicamente viáveis e tecnicamente adequadas para a problemática das obras no espaço urbano.

\section{Objetivos}

Destacam-se como objetivos do projeto o diálogo pedagógico entre estudantes e público-alvo a respeito das possibilidades de redução de custos de obras; das tecnologias de baixa demanda de recurso; da ajuda mútua para execução de obras; das possibilidades de capacitação; do aproveitamento dos recursos humanos disponíveis; e, também, da busca por fontes de financiamento. As ações possibilitam, ainda, aos estudantes aplicar os conhecimentos obtidos ao longo do curso em situações reais e desenvolver o aprofundamento conceitual em variados tipos de projetos, bem como a formação profissional por meio do aprendizado em novas áreas que nem sempre podem ser exploradas nos cursos de graduação, como os conceitos de ética profissional e relação interpessoal.

\section{Equipe e Metodologia}

Atualmente, a equipe é composta por um estudante bolsista, 23 estudantes voluntários, sendo que 21 são da Engenharia Civil e 2, da Arquitetura e Urbanismo; 2 engenheiros voluntários, 1 professor orientador e diversos professores colaboradores.

Em relação à forma de obtenção de trabalhos, tanto a divulgação quanto a captação dos projetos a serem realizados se dão em locais de referência dos bairros carentes da cidade, como, por exemplo, associações e igrejas. Em função da demanda e da necessidade da população, são elaborados os projetos, os quais podem ser: estruturais, arquitetônicos, hidráulicos e de saneamento, de prevenção e combate a incêndio, de transportes e de capacitação, entre outros. São oferecidos também serviços de orçamentação, consultoria e acompanhamento de obras.

O público-alvo são famílias carentes de Viçosa e região, além de associações comunitárias, creches e lar de idosos. O projeto visa, ainda, a dar suporte e apoio a iniciativas de ONG's como o "Engenheiros sem Fronteiras" e associações como a "Casa das Mulheres", uma vez que se acredita que a troca de experiências é a melhor forma de disseminar o que se tem a ensinar e a aprender.

A metodologia consiste em um conjunto de práticas que estimula, além da realização de atividades nas comunidades carentes, a vivência prática requerida pelos estudantes de conteúdos como a execução dos projetos elaborados e networking, por exemplo. 


\section{Ações}

Diversas ações em várias frentes foram empreendidas dentro do projeto de extensão "Engenharia Pública" no período de fevereiro de 2014 a maio de 2015. As mais relevantes citadas a seguir:

- Trabalho de divulgação:

- Visitas ao bairro Nova Viçosa, com o objetivo de informar à população o local sobre o oferecimento de assistência e auxílio na elaboração de projetos para construção e reforma e com o de captar demandas;

Criação e manutenção do Blog Engenharia Pública (http://engenhariapublica.blogspot.com.br);

- Criação e manutenção da página no Facebook do Engenharia Pública (https:// www.facebook.com/engpublica);

- Elaboração de projetos e consultorias técnicas finalizados.

- Projeto arquitetônico e estrutural de uma residência unifamiliar de dois pavimentos na comunidade Sítio Periquito, Coimbra, MG.

- Projeto arquitetônico e estrutural de uma residência unifamiliar de dois pavimentos na comunidade de Bom Jesus, Viçosa, MG.

- Projeto arquitetônico e estrutural da Capela do Marengo, na zona rural de Coimbra, MG - vide Figura 1:
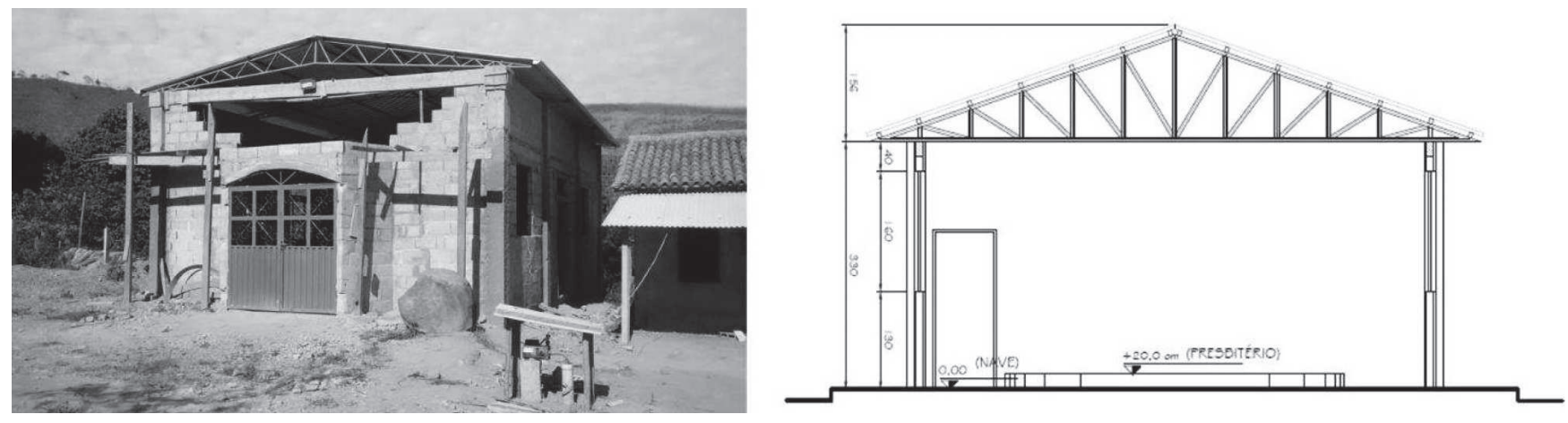

Figura 1 - Projeto arquitetônico e estrutural da Capela do Marengo, na zona rural de Coimbra-MG.

Fonte: Elaborado pelos autores, 2014.

- Projeto de recuperação de uma travessa junto ao planejamento de um escadão no bairro Centro, de Viçosa, em parceria com a Edifica Consultoria, Empresa Júnior de Engenharia Civil em andamento. Projeto estrutural e hidrossanitário do Centro Educacional e Ação Social São Sebastião, que visa a atender cerca de 200 (duzentas) crianças, do berçário à pré-escola, no bairro Inácio Martins, Viçosa, MG.

- Estudo para a verificação estrutural e o dimensionamento de elementos de reforços do Santuário de Urucânia, MG.

- Projeto estrutural e arquitetônico para a construção de um segundo pavimento na Corporação Musical Santíssima Trindade.

- Estudo da problemática da mobilidade urbana no município de Coimbra, MG, incluindo visitas à cidade, visando a elaboração de projetos e orientações técnicas para a melhoria do trânsito e propostas de alternativas para vias de acesso ao futuro frigorífico da região.

- Projeto de Prevenção e Combate a Incêndio e Pânico para a REBUSCA, Creche vinculada à Igreja Presbiteriana de Viçosa, Viçosa, MG.

\section{Material técnico e de apoio às comunidades interessadas}

- Desenvolvimento de um curso de capacitação, em parceria com o Engenheiros sem Fronteiras e com a Casa da Mulher, sobre Construção Civil, Segurança do Trabalho e Empreendedorismo, em Viçosa, MG; 
- Elaboração de um estudo de custo médio de edificações de padrão popular em Viçosa e Região consistindo no orçamento de quatro protótipos a partir de preços de materiais e mão de obra praticados localmente (gerou um Trabalho de Conclusão de Curso);

- Contribuições na elaboração de minicursos e workshops para as comunidades interessadas.

\section{Políticas públicas}

- Sondagem contínua junto aos órgãos públicos na busca de soluções para a problemática da habitação em Viçosa, incluindo participação em reuniões e visitas a órgãos da prefeitura na busca de alternativas.

\section{Metas}

O projeto tem como meta atingir um modelo de engenharia pública funcional e efetivo para Viçosa e região. Para isso, almeja-se o envolvimento de estudantes, prefeitura e profissionais, em esforço conjunto, para oferecer soluções técnicas de qualidade, segurança e de viabilidade econômica à sociedade de modo geral.

Visa-se a transcender o limite físico da Universidade Federal de Viçosa e, com isso, levar à cidade a excelência do ensino da Instituição no que tange à Engenharia, cujo conhecimento, de fato, é público. Pretende-se, dessa forma, realizar a implantação de medidas que efetivamente promovam melhorias na infraestrutura urbana, isto é, no trânsito, no sistema de abastecimento, saneamento e drenagem de água, e tantos outros.

Além disso, pretende-se ainda sensibilizar a sociedade de que o projeto de engenharia não é um obstáculo burocrático ou um problema a ser vencido, mas, sim, uma solução que oferece economia, conforto e segurança ao usuário.

\section{Conclusão}

Diante da situação urbana vigente na cidade de Viçosa e região, em consonância com a realidade de todo o país, em que as ruas não suportam mais carros, a drenagem é insuficiente - e, por vezes, até inexistente - e o processo de construção é precário e oneroso, vê-se, pois, de fato, a necessidade do projeto, que visa a minimizar e/ou extirpar tais tipos de problemas.

Ao entender que a construção de uma sociedade mais justa passa pela mobilização, organização e participação popular (SOUZA, L. M, 2014), o Engenharia Pública abarca questões que vão desde as manifestações patológicas relacionadas à má execução da obra aos riscos inerentes de projetos elaborados e executados sem respaldo técnico. Neste cenário, surgem, por exemplo, os projetos de combate a incêndio da REBUSCA e estrutural da creche São Sebastião, em que o primeiro atua de forma a prevenir e minimizar tragédias; e o segundo, a promover educação de qualidade e ainda possibilidade de empregos para as mães das crianças atendidas.

Observa-se, assim, que o projeto mais do que construir obras, visa a construir possibilidades na vida daqueles que, de alguma forma, fazem parte da trajetória em formação do Engenharia Pública. A máxima de Mahatma Ghandi: "Seja a mudança que você quer ver no mundo." cabe aqui ao se observar que, por meio do projeto, constrói-se um pouco daquilo que o mundo, de fato, precisa, isto é, educação, justiça, dignidade e conhecimento.

\section{Agradecimento}

Faz-se um agradecimento especial a todos os participantes do projeto Engenharia Pública, que apoiaram a iniciativa de relatar essa experiência de vida.

\section{Referências Bibliográficas}

MILLEN, E B. Um projeto estrutural pelo preço de uma panqueca. O Empreiteiro: 2012. Disponível em: $<\mathrm{h} \mathrm{t} \mathrm{t} \mathrm{p} \mathrm{:} \mathrm{/} \mathrm{/} \mathrm{w} \mathrm{w} \mathrm{w.} \mathrm{o} \mathrm{e} \mathrm{mpreiteiro.com.br} \mathrm{/} \mathrm{P} \mathrm{ublic} \mathrm{a} \mathrm{coes} \mathrm{/} 11667 /$ Um_projeto_estrutural_pelo_preco_de_uma_panqueca_.aspx>. Acesso em: 25 maio 2015. 
SOUZA, L. M. Curso de formação de educadores jovens do campo: uma trajetória em formação. Revista ELO - Diálogos em Extensão, Viçosa, v. 03, n. 01, p. 78-84, jun. 2014. Disponível em: <http:// www.elo.ufv.br./docs/v3n1/relato-2.pdf>. Acesso em: 25 maio 2015. 